\title{
Methods of deconditioning persisting avoidance: Diazepam as an adjunct to response prevention
}

\author{
JUDITH E. GORMAN, JAMES D. DYAK, and LARRY D. REID \\ Rensselaer Polytechnic Institute, Troy, New York 12181
}

\begin{abstract}
Rats were trained to avoid footshock during three daily sessions, 100 trials/session, in an automated one-way avoidance chamber. Subsequent to training, footshock was terminated and the rats' persistence in responding was tabulated. Between training and the test of persisting avoidance, three groups of rats received a response prevention (RP) treatment and one group received no RP. RP consisted of forcing the rats to stay on the once-dangerous grid for $5 \mathrm{~min}$, once a day for 4 days. Two groups received RP under the influence diazepam ( 25 or $50 \mathrm{mg} / \mathrm{kg}$, p.o.). With respect to persisting avoidance, groups ordered themselves from most to least as: (1) placebo with no RP, (2) high dose of diazepam with RP, (3) low dose of diazepam with RP, and (4) placebo with RP. Because RP with placebo was the most effective treatment, it was concluded that diazepam is inefficient as an adjunctive treatment for overcoming persisting anxiety/fear/avoidance.
\end{abstract}

Avoidance extinguishes slowly and persists far beyond the termination of the previously applied aversive stimulation (Solomon, Kamin, \& Wynne, 1953). The persistence of nonutilitarian avoidance, and the accompanying emotionality, are thought to be characteristic of a wide variety of neurotic behaviors. Strategies, therefore, have been devised for controlling or reconditioning such anxiety/fear/avoidance in an effort to remediate neurotic conditions. Laboratory procedures have also been developed to test the efficacy of the various methods.

One such laboratory procedure, developed and used extensively by Baum (1970), used rats in an automated one-way avoidance chamber. Rats are trained to avoid high-intensity footshock by jumping to a retractable ledge above a grid floor. The rat is allowed to remain on the ledge for a limited time, after which the ledge retracts, forcing the rat back onto the grid and beginning a new trial. The ledge is then returned and the rat is given a brief period to climb to the ledge to avoid shock. After the avoidance is well established, footshock is terminated but the opportunity to respond continues, and rats, without special treatments, continue to respond for many trials even though there is no chance of footshock.

A variety of treatments have been tested for the ability to modify persisting avoidance (Baum, 1970; Reid, 1973, 1977). One treatment, called response prevention (RP), involves forcing the rat to stay on the once-shocking grid by keeping the ledge out of the chamber. Prolonged periods of RP lead to reduced persisting avoidance. A variety of treatments have been programmed as adjuncts to RP to see how they might

This work was supported by Grant DA02044 from the National Institute on Drug Abuse, Department of Health, Education, and Welfare. modify persisting avoidance, including the administration of a number of psychotropic agents (Taub, Taylor, Martin, Kelley, Becker, \& Reid, 1977).

Taub et al. (1977) found that many drugs were not effective adjuncts to RP. Chlordiazepoxide, for example, actually led to more persisting avoidance than placebo. The conclusion reached by Taub et al. based on their data and others (e.g., Kamano, 1973) was that giving such drugs to control anxiety/fear/avoidance was not only ineffective but potentially detrimental. Perhaps, however, the Taub et al. (1977) procedure, using a single, relatively brief period of RP under the influence of a drug, provided a peculiar test of a drug's potential to modify persisting avoidance. Becker, Magnuson, and Reid (1977) did show that a counterconditioning treatment was effective as an adjunct to RP using the same basic procedure. It is possible, nevertheless, that with a longer RP period and more RP periods under the influence of drug, it can be shown that drugs are efficient adjuncts to RP. The present study used four RP sessions and tested the effect of diazepam, a widely used drug not previously tested for its effect on persisting avoidance.

\section{METHOD}

The subjects were 48 (350 to $400 \mathrm{~g}$ ) male, experimentally naive, Sprague-Dawley-derived rats. The individually housed rats had food and water always available. The automated apparatus was a clear plastic box $(30 \times 27.5 \times 38 \mathrm{~cm})$ fitted with an electrifiable grid floor and a retractable ledge. The ledge was $27.5 \mathrm{~cm}$ wide and, when not retracted, extended $6 \mathrm{~cm}$ in to the box, $14 \mathrm{~cm}$ above the floor. Shock intensity was always $1.3 \mathrm{~mA}$ and was generated by a Grason-Stadler shock source and scrambler. The subject's presence on the ledge was detected by a photocell system.

All subjects were trained with a standard procedure. The experimentally naive rat was placed on the grid. After $10 \mathrm{sec}$, shock began and continued until the rat escaped to the ledge. 
The rat remained on the ledge for $30 \mathrm{sec}$, then the ledge retracted, dropping the rat back onto the grid. As soon as the ledge was fully retracted, it returned to the box and set the circumstances for the next trial. The subject could avoid shock by climbing to the ledge within $10 \mathrm{sec}$, otherwise it was shocked until it escaped to the ledge.

Training sessions were 100 trials; the session ended with the subject on the ledge. Each subject received one training session a day for 3 consecutive days, a total of 300 trials. At the end of the 299th trial, each rat was given $1 \mathrm{sec}$ of inescapable shock to insure that all subjects received an equally recent experience of footshock prior to treatment. Footshock was then terminated and not reinstated for the remainder of the experiment.

Subsequent to training, the subjects were randomly divided into four groups ( $n=12 /$ group) for treatment with a high dose of diazepam $(50 \mathrm{mg} / \mathrm{kg}$, orally) before $R P$, a low dose of diazepam $(25 \mathrm{mg} / \mathrm{kg}$, orally) before $R P$, a placebo before $R P$, or a placebo with no RP. The placebo was the carrier of diazepam (water and gum arabic) in a volume comparable to the high dose of diazepam. On 4 consecutive days beginning the day after training, each rat was intubated with diazepam or placebo. After $30 \mathrm{~min}$, each rat received RP treatment or no RP treatment. A rat receiving no RP was placed in a plastic pail alongside the apparatus for the treatment time. During RP the subject was on the grid floor with the ledge retracted. Rats received a total of $20 \mathrm{~min}$ of RP, $5 \mathrm{~min}$ of $\mathrm{RP}$ on each of 4 consecutive days.

The first four subjects of each group were tested for perseveration of responding $24 \mathrm{~h}$ after the last treatment. At the end of the test for perseveration of responding for the first four subjects of each group, it was noted that the drug might not have been completely metabolized. For this reason, the remaining subjects were tested $48 \mathrm{~h}$ after treatment. Since the results of the first subjects were similar to those of the others, the procedural difference was ignored in analyses of results.

Testing began by placing the subject on the ledge. After $30 \mathrm{sec}$, the ledge retracted and trials were started. These trials were the same as the training trials except, of course, that the subject never received footshock. After the first 3 min of testing had elapsed, the subject was picked up, handled briefly in a standard way, and replaced on the ledge, a procedure designed to eliminate freezing that might occasionally produce a spuriously low score (Taub et al., 1977). Testing continued until the subject reached criterion by remaining on the grid floor continuously for $5 \mathrm{~min}$ or until it had accumulated 535 trials.

\section{RESULTS}

As is typical in this training paradigm, rats took the most shock on the first trials of Day 1 of training. Across all subjects, they took a mean of $109.9 \mathrm{sec}$ of shock during the first 100 trials and 7.7 and $3.1 \mathrm{sec}$ of shock, respectively, during the two subsequent training sessions. An analysis of variance (ANOVA) of the amount of shock taken during the first training session, with rats grouped according to their eventual treatments, provided no evidence to conclude that the groups differed prior to treatment $[F(3,44)=.73]$. A similar analysis using the scores of total shock taken across the three training sessions yielded similar results. Furthermore, the correlations between performances during training (amount of shock taken) and performances after treatment (trials to criterion) were small and statistically nonsignificant. The conclusion to be drawn from these analyses, then, is that the groups did not differ significantly prior to treatment, and differences seen after treatment were the result of the various treatments.

Wise and Dawson (1974) have pointed out that diazepam leads to eating in rats. To confirm that effective doses were given, we tabulated the incidence of eating in the home cage of rats given diazepam. In every instance, the rats began eating within the $30 \mathrm{~min}$ allowed for the drug to take effect.

As would be expected, the group receiving no RP treatment showed strong persisting avoidance and the group receiving RP with placebo showed considerably less persisting avoidance (Figure 1). Groups receiving doses of diazepam with RP responded considerably more than the group receiving RP with placebo. An ANOVA of the data used to derive Figure 1 yielded $F(3,44)=4.24(p<.01)$. A Student $t$ test comparing scores of placebo with no RP and scores of placebo with $R P$ yielded $t(22)=2.90(p<.01)$. The comparisons of interest, of course, are between scores of the placebo group and the scores of the groups receiving high and low doses of diazepam, all of which received RP. These comparisons yielded $\mathrm{t}(22)=1.69(\mathrm{p}<.10)$ for the low dose compared to placebo and $t(22)=2.07(p<.05)$ for the high dose compared to placebo. Nonparametric comparisons yielded similar results; for example, the MannWhitney $U$ comparing the low dose to placebo yielded $\mathrm{U}=18(\mathrm{p}<.02)$ and for high dose to placebo, $U=25$ $(p<.01)$.

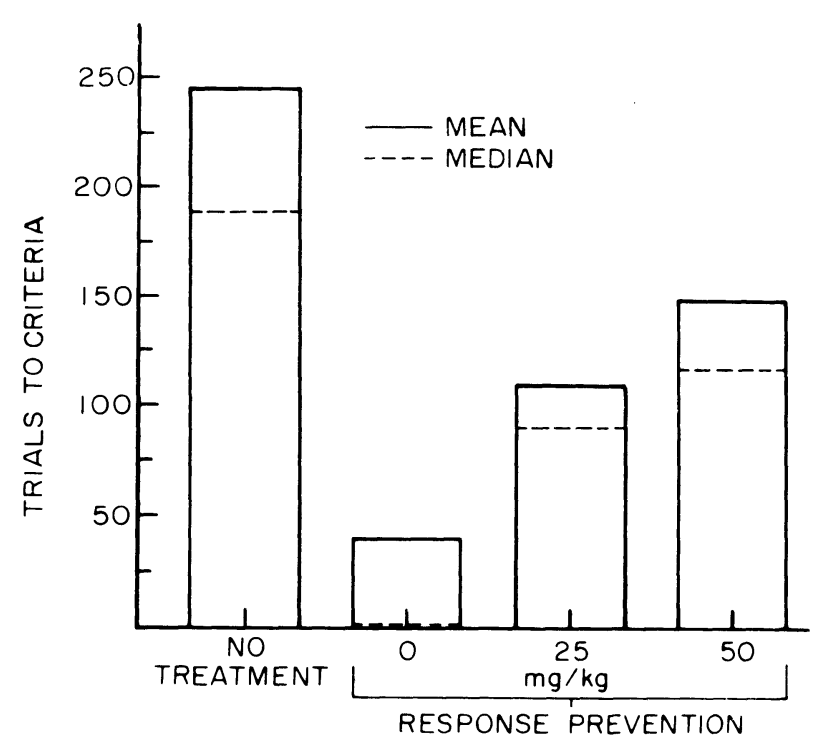

Figure 1. Mean and median trials to criteria, measures of persisting avoidance, are depicted. The no-treatment group received no response prevention; the three remaining groups received $5 \mathrm{~min}$ of response prevention in addition to their respective drug treatments on each of 4 consecutive days. 


\section{DISCUSSION}

As would be expected, rats receiving no $\mathrm{RP}$ treatment responded many times before meeting criteria (Solomon et al., 1953), and rats receiving placebo with RP took reliably fewer trials (Baum, 1970). These results confirm that the circumstances for an adequate test of diazepam as an adjunct to RP were established.

Diazepam not only failed to add to the effectiveness of RP but actually led to reliably greater persisting avoidance compared to placebo with RP. This study, therefore, supports the conclusion derived from similar studies (Kamano, 1973; Taub et al., 1977) that the benzodiazepines are not efficient adjuncts to RP, particularly when performance after treatment and without drug is the measure of interest. Perhaps previous studies were inadequate because the total RP period was short in relationship to the amount of training and because there was only one session under the influence of drug. This study, however, programmed a relatively extensive total RP period (notice the marked reduction of responding by the RP-placebo group) and gave RP and drug on four occasions. Yet the drugged group showed more anxiety/fear/avoidance than the group given RP alone. Analogues of behavioral treatments in this paradigm have led to marked reduction in persisting avoidance even with rats trained over 1,000 trials (Reid, 1977; Voss, Mejta, \& Reid, 1974). Clinical trials of the behavioral strategies have also been highly successful (Franks \& Wilson, 1973; Wolpe, 1973). These observations all lead to the suggestion that the use of minor tranquilizers is a relatively inefficient strategy for managing neurotic anxiety, and that behavioral strategies are more efficacious.

\section{REFERENCES}

BAUM, M. Extinction of avoidance responding through response prevention (flooding). Psychological Bulletin, 1970, 74, 276-284.

Becker, B. M., Magnuson, D. F., \& Reid, L. D. Methods of deconditioning persisting avoidance: Intracranial stimulation as a counterconditioner. Physiological Psychology, 1977, 5, 73-75.

Franks, C. M., \& Wilson, G. Annual review behavior therapy: Theory and practice. New York: Brunner/Mazeo, 1973.

Kamano, D. K. Using drugs to modify the effects of response prevention on avoidance extinction. Behavior Research and Therapy, 1973, 79, 107-109.

REID, L. D. Processes of fear reduction in systematic desensitization: An addendum to Wilson and Davison (1971). Psychological Bulletin, 1973, 79, 107-109.

REID, L. D. Methods of deconditioning persisting avoidance. Scandinavian Journal of Behavior Therapy, 1977, Supp. 4, 107.

Solomon, R. L., Kamin, L. T., \& Wynne, L. C. Traumatic avoidance learning: The outcome of several extinction procedures with dogs. Journal of Abnormal and Social Psychology, 1953, 48, 291-302.

Taub, J., Taylor, P., Martin, S., Kelley, K., Becker, B., \& REID, L. Methods of deconditioning persisting avoidance: Drugs as adjuncts to response prevention. Physiological Psychology, 1977, 5, 67-72.

Voss, E., Mejta, C., \& Reid, L. Methods of deconditioning persisting avoidance: Response prevention and counterconditioning after extensive training. Bulletin of the Psychonomic Society, 1974, 3, 345-347.

Wise, R. A., \& Dawson, V. Diazepam-induced eating and lever pressing for food in sated rats. Journal of Comparative Physiological Psychology, 1974, 86, 930-941.

Wolpe, J. The practice of behavior therapy. New York: Pergamon Press, 1973.

(Received for publication April 11, 1979.) 